\title{
The Use of Over-The-Counter (OTC) Medications by University Students During Examinations in Saudi Arabia: A Cross-Sectional Study
}

\author{
Khalid Orayj' \\ Sultan M Alshahrani (iD) \\ Ali M Alqahtani iD ${ }^{2}$ \\ Nawal Alasmari ${ }^{3}$ \\ Amjad Al Abo Atef ${ }^{4}$ \\ Hadeel S Jrais (D) ${ }^{3}$ \\ Dalia Muslot ${ }^{5}$ \\ 'Department of Clinical Pharmacy, \\ College of Pharmacy, King Khalid \\ University, Abha, Saudi Arabia; \\ ${ }^{2}$ Department of Pharmacology, College \\ of Pharmacy, King Khalid University, \\ Abha, Saudi Arabia; ${ }^{3}$ Al Nahdi Pharmacy, \\ Abha, Saudi Arabia; ${ }^{4}$ Al Dawaa Pharmacy, \\ Abha, Saudi Arabia; ${ }^{5}$ College of \\ Pharmacy, Medicine and Health Sciences \\ Faculty, University of Hodeidah, Al \\ Hudaydah, Yemen
}

Purpose: During examinations, many students use various over-the-counter (OTC) drugs to improve their concentration or treat exam-related medical symptoms. The purpose of this study was to scrutinize the use of OTC drugs during examinations in Saudi Arabia.

Materials and Methods: A cross-sectional study was designed, consisting of online, selfadministered questionnaires comprising 27 items, including the awareness, knowledge, and attitude of students toward OTC drug use during examinations. A logistic regression model was fitted to determine factors that predict OTC drug use. The data were analyzed using Statistical Package for Social Science (SPSS).

Results: A total of 463 (92.6\%) completed questionnaires were received from 500 recruited participants. Among participants, 58.5\% were women, $47.9 \%$ were 22 years or older and completing their final year of study, and $44.1 \%$ of students preferred not to disclose their monthly income. The most common cause $(35.6 \%)$ for OTC drug use during the examination period was headache, followed by pain $(21 \%)$, fever $(16.6 \%)$, and cough $(8.2 \%)$. The most commonly used medication were painkillers, antipyretics, cough and cold medications, and vitamins $(57.2 \%$, $16.4 \%, 11 \%$, and $7.3 \%$, respectively). Male students showed a significant lack of awareness and knowledge regarding the safety and reasons for OTC drug use compared with their female counterparts and were less likely to read the medication leaflet before use $(p<0.001$, odds ratio [OR]: 0.36, confidence interval [CI]: 0.23-0.57) and did not know which drugs require prescriptions ( $\mathrm{p}<0.001$, OR: $0.41, \mathrm{CI}: 0.27-0.63)$. Other significant factors that predicted OTC drug use included age, university level, and drug income.

Conclusion: The most common reported cause for OTC drug use during examinations among students was headache. Sex, age, university level, and monthly income were significant factors affecting OTC drug use during examinations.

Keywords: OTC, headache, pain, students, Saudi Arabia

\section{Introduction}

The self-medicating practice of using over-the-counter (OTC) medications is more common than prescription drug use worldwide. ${ }^{1}$ Non-prescription drugs or OTC medications refer to all drugs that can be legally purchased without requiring a prescription from a registered medical practitioner. As a general rule, OTC drugs are primarily used to treat conditions that do not require direct medical attention or supervision, and OTC drugs must be demonstrated to be reasonably safe and well-tolerated. ${ }^{2,3}$
Correspondence: Ali M Alqahtani Department of Pharmacology, College of Pharmacy, King Khalid University, Abha, Saudi Arabia

Tel/Fax +966-54-8502323

Email amsfr@kku.edu.sa 
Self-medication also refers to the use of medications or herbs based on one's own initiative or the advice of others, such as friends, relatives, pharmacists, and mainstream magazines and newspapers. Self-medication represents a global healthcare epidemic, particularly in developed countries, often driven by economic and social motivations. ${ }^{4-6}$

The use of OTC drugs is associated with many advantages, including decreased doctor visits and lower costs compared with prescription drugs. However, the misuse of OTC drugs can result in adverse reactions, drug interactions, overdosing, and other medication-related issues. Therefore, the public should be trained in the safe use of OTC drugs to increase their knowledge and understanding of potential dangers and promote responsible self-care. When prescription drugs are used in accordance with a physician's recommendations for specific diagnoses, they are effective for treating illnesses; however, some prescription medications can be purchased without a prescription. ${ }^{7-9}$

These medications have huge impacts on individuals and the community. Saudi Arabia is known for its high use of OTC drugs. Irresponsible self-medication practices are popular in Saudi Arabia and continue to present a major problem because people are often unsure whether the medicines they have purchased are prescription-only or OTC medications. ${ }^{9-11}$

Previous studies have shown that a lack of knowledge regarding OTC drugs is prevalent at comparable rates among both medical and non-medical students, although some variations in the medical indications and types of drugs used have been identified. Universities should improve student awareness regarding the dangers of taking prescription-only drugs, such as antibiotics, and the risks these drugs may pose to overall well-being. ${ }^{11,12}$

Many students tend to use various OTC and non-OTC substances to increase their concentration or alertness when studying for exams. Stimulants, opioids, OTC and non-OTC analgesics, antihistamines, and certain conventional and alternative drugs, such as Ginkgo biloba, are all substances that students typically misuse, both in general and during examinations. ${ }^{12-14}$

This study aimed to evaluate the use of OTC drugs among students during examinations at King Khalid University (KKU), Abha, Saudi Arabia.

\section{Materials and Methods}

\section{Study Design and Study Area}

This study was designed as a descriptive, cross-sectional study, conducted from May to July 2020 among undergraduate students enrolled at KKU, Abha, Saudi Arabia. The study included students at three main campuses in Abha City, including the Guraiger campus (male), Alsamer campus (female), and Almahalah campus (freshmen). Approximately 60,000 regular students are studying at $\mathrm{KKU}$, and students from all campuses were considered in this study. The time of examination was the targeted period for this study.

\section{Study Population and Sample Size Calculation}

With the assumption of a single population proportion, the sample size was calculated using the sample size estimation formula. The prevalence of self-medication was assumed to be $49.3 \%$, based on the findings of a previous study conducted at the Imam Abdulrahman Alfaisal University, Dammam, Eastern region, Saudi Arabia. ${ }^{15}$ The margin of error was set to $5 \%$, and the confidence interval (CI) was set to $95 \%$, with $5 \%$ precision. The sample size was calculated as follows:

$$
\mathrm{n}=(\mathrm{Z} \alpha / 2)^{2} \times \mathrm{p}(1-\mathrm{p}) /(\mathrm{d})^{2}=(1.96)^{2} \times 0.49(1-0.49) /
$$
$(0.05)^{2}$

Based on these assumptions, a minimum sample size of 384 students, both male and female, from medical and non-medical colleges, was required for this study.

\section{Study Tool and Data Collection}

The questionnaire used in this study was adapted from previous studies. ${ }^{7,11}$ A panel of three academicians reviewed the questionnaire for scientific and ethical purposes and determined its suitability for the research subjects. The questionnaire was pilot-tested on a convenience sample of 12 students to evaluate the validity and internal reliability of the survey. The Cronbach's alpha value was calculated as 0.81 . The pilot study results were not included in the current study analysis. The validated questionnaire was distributed in English, although an Arabic version was also available. The survey consisted of 27 questions divided into six parts; part one collected the socio-demographic characteristics of all study participants, including sex, age, and level of study; part two collected information regarding the participants' knowledge of OTC drug safety; part three asks for the underlying reasons driving OTC drug use; part four evaluated participants' attitudes toward OTC drug use during examinations; part five asked about the students' knowledge regarding the indications for OTC drug use; part six asked about common reasons for OTC use. A nominal scale of 
Yes/No-type-questions was utilized to evaluate 18 items regarding the knowledge of OTC drug safety, reasons for OTC drug use, and the indications for OTC drug use.

The study was conducted using Google forms, and the survey was distributed through various social media platforms. The purpose of the study was clearly explained to participants at the beginning of the survey. The participants were asked for their voluntary consent to participate in the study before beginning the online survey. Only university students 18 years and older were included in the study.

\section{Data Analysis}

The collected data were examined for completeness, coded, and entered into SPSS version 23. Descriptive statistical analyses, presented as the frequency and percentage, were performed for demographic data and knowledge responses. Logistic regression was fitted to identify factors associated with OTC drug knowledge and the reasons for using OTC drugs during examinations. All independent factors (sex, age, university level, and monthly income) were considered as a priori determinants and were retained in the multivariate model, regardless of their significance in the bivariate model. Odds ratios (ORs) and 95\% confidence intervals (CIs) were utilized to detect correlations between dependent and independent variables. On multivariate analysis, $P<0.05$ was considered significant.

\section{Ethical Considerations}

This study was conducted in compliance with the World Medical Association (WMA) Declaration of Helsinki: Ethical principles for medical research involving human subjects amended by 59th WMA (no. PHRC/HC/11/13), 2013, Seoul, Korea. The study was approved by Research Ethics Committee at KKU, Saudi Arabia. (ECM\# 2020-3307). The purpose of the study was clearly explained to participants at the beginning of the survey. All participants were asked for their consent to participate in the study before being given the survey. Only university students 18 years and older were included in the study. The responses were maintained anonymous and confidential, and the participants were notified of their anonymity before beginning the questionnaire. None of the participants' personal information was collected.

\section{Results}

\section{Demographic Results}

A total of 463 completed questionnaires were received from 500 initially recruited participants (response rate: 92.6\%).
More than half of the participants were women (58.5\%), and the majority were 22 years or older and in their final year of study $(47.9 \%)$ and preferred not to report their monthly income $(44.1 \%)$. The demographic results are summarized in Table 1. The most commonly reported reason for using OTC drugs during examinations was headache $(35.6 \%)$, followed by pain (21\%), fever (16.6\%), and cough (8.2\%). The most commonly used medications were painkillers, antipyretics, cough and cold medications, and vitamins $(57.2 \%, 16.4 \%, 11 \%$, and $7.3 \%$, respectively).

\section{Participants' Knowledge and Attitudes Regarding OTC Drug Safety and Reasons for Use}

The results showed that most of the participants answered positively that herbal and natural products used to enhance memory have no adverse effects $(75.4 \%)$, and $79 \%$ agreed that the long-term use of OTC drugs would lead to serious side effects. The majority of respondents stated that they read the medication leaflets and indicated that they were aware of which drugs required prescriptions $(65.2 \%$ and $62.4 \%$, respectively). However, more than half of the students $(54.4 \%)$ responded that the overuse of acetaminophen was safe during examinations, although most participants agree that non-steroidal anti-inflammatory drug (NSAID) products were harmful if misused (88.8\%).

Table I Demographic of Respondents

\begin{tabular}{|c|c|}
\hline Demographic & $\begin{array}{l}n(\%) \\
N=463\end{array}$ \\
\hline Sex (Female) & $271(58.5)$ \\
\hline \multicolumn{2}{|l|}{ Age group } \\
\hline Equal or less than 18 years & $77(16.6)$ \\
\hline |9-2I years & II $2(24.2)$ \\
\hline 22 and more years & $247(59.2)$ \\
\hline \multicolumn{2}{|l|}{ Educational level } \\
\hline$I^{\text {st }}$ year of university & $97(2 \mathrm{I})$ \\
\hline $2^{\text {nd }}$ year & $35(7.6)$ \\
\hline $3^{\text {rd }}$ year & $109(23.5)$ \\
\hline $4^{\text {th }}$ of final year & $222(47.9)$ \\
\hline \multicolumn{2}{|l|}{ Monthly income } \\
\hline Less than 5000 Saud Riyal (SR) & $84(18.1)$ \\
\hline $5000-1000$ SR & $79(17.1)$ \\
\hline More than 10,000 SR & $96(20.7)$ \\
\hline Prefer to not mention & $204(44.1)$ \\
\hline
\end{tabular}


Table 2 Respondents' Knowledge About the Safety and Use of OTC Drugs

\begin{tabular}{|c|c|}
\hline Question & $\begin{array}{l}\text { Response } \\
(\mathbf{n}, \%)\end{array}$ \\
\hline Use of herbal/natural products to improve memory and attention has no harmful consequences for the human body. & Yes $(349,75.4)$ \\
\hline Long term use of OTC drugs can cause serious side effects & Yes $(366,79)$ \\
\hline I read medication leaflet before using any medication & Yes $(302,65.2)$ \\
\hline I Know that the drug I bought from the pharmacy needs a prescription from the physician & Yes $(289,62.4)$ \\
\hline Over using Panadol extra is very safe during exam period & Yes $(252,54.4)$ \\
\hline $\begin{array}{l}\text { NSAID drugs (eg ibuprofen) may cause harm to your kidneys if they are misused. Also, NSAID drugs (ibuprofen) may } \\
\text { cause stomach ulcer }\end{array}$ & Yes $(4 I I, 88.8)$ \\
\hline I use OTC drugs because the disease is not dangerous & Yes $(403,87)$ \\
\hline I use OTC drugs because I know how treat my self & Yes $(395,85.3)$ \\
\hline I use OTC drugs because they are more convenient and easy to use & Yes $(315,68)$ \\
\hline I use OTC drugs to save my time & Yes $(37 I, 80.1)$ \\
\hline I use OTC drugs because the cost of physician visit is too high & Yes $(294,63.5)$ \\
\hline I use OTC drugs during exams to treat my headache & Yes, $(399,86.2)$ \\
\hline OTC drugs are cheap and easily available in Saudi Arabia that is why all people use them & Yes $(372,80.3)$ \\
\hline Advertising is the main cause that people use ОTC & Yes $(307,66.3)$ \\
\hline $\begin{array}{l}\text { Because of the accessibility of OTC medications and my confidence in their safety, I use them heavily during the exam } \\
\text { time. }\end{array}$ & Yes $(35 \mathrm{I}, 75.8)$ \\
\hline During exam period many students may try medicines according to friend's suggestion & Yes $(277,59.8)$ \\
\hline Because of the pharmacist's consultation, I feel more comfortable using OTC medications. & Yes $(383,82.7)$ \\
\hline The sedative effect of antihistamines (flu medications) makes students misuse them during exams & Yes $(4 \mid 8,90.3)$ \\
\hline
\end{tabular}

The main reasons for using OTC drugs during examinations were that they were not dangerous $(87 \%)$, followed by students know how to treat themselves (85.3\%), OTC drugs are cheap and easy to access $(80.3 \%)$, to save students time (80.1\%), and the cost of visiting physicians is high (63.5\%). Commercial advertising was the main driver of increasing participants' use of OTC drugs $(66.3 \%)$. The respondents generally agreed that OTC drugs are convenient and easy to use $(68 \%)$.

Most of the participants (75.8\%) may be led to use OTC drugs during exams due to the belief that they are safe. A friend's suggestion to try OTC drugs was an important driver of their decisions during examinations (59.6\%). However, most participants would consult pharmacists and were comfortable doing so (82.7\%). Most of the respondents showed positive attitudes when asked about the misuse of sedative antihistamines during examinations (90.3\%). All respondents' knowledge results about the safety and use of OTC drugs are listed in Table 2.

\section{Correlations Between Different Factors and the Use of Medicines without Prescriptions}

As summarized in Table 3, the logistic regression revealed a significant association between several variables and students' knowledge regarding OTC use during examinations. Male students showed a significant lack of awareness and knowledge regarding OTC drug safety and reasons for using OTC drugs. Compared with their female counterparts, male students were less likely to read the medication leaflet before use $(\mathrm{p}<0.001$, OR: $0.36, \mathrm{CI}$ : $0.23-0.57)$ and did not know which drugs required prescriptions $(\mathrm{p}<0.001$, OR: 0.41 , CI: $0.27-0.63)$. The 


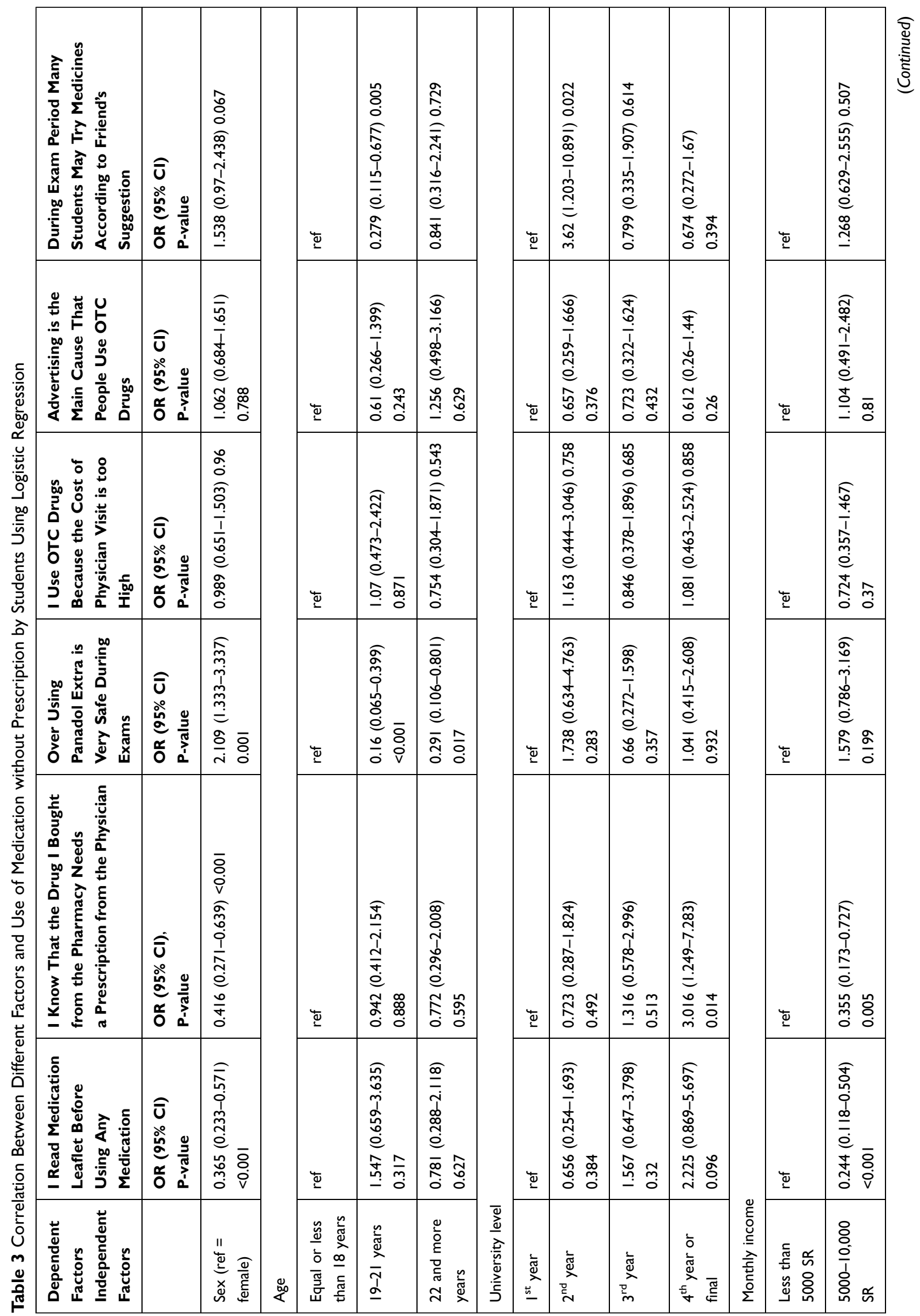




\begin{tabular}{|c|c|c|}
\hline 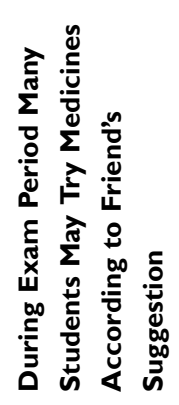 & 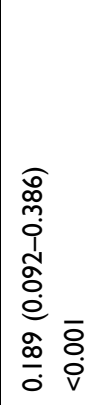 & 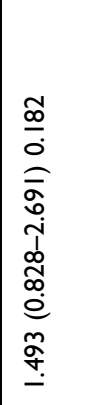 \\
\hline 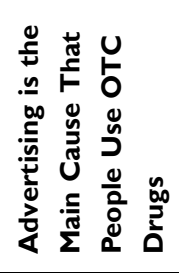 & 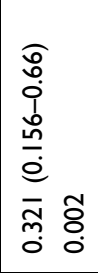 & 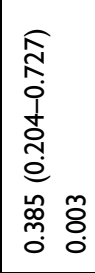 \\
\hline 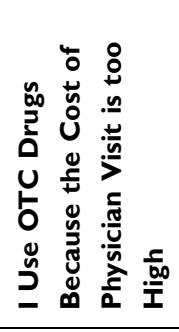 & 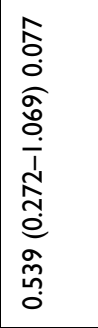 & 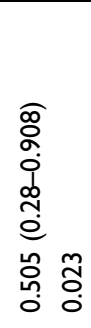 \\
\hline 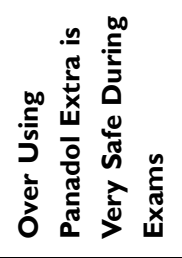 & 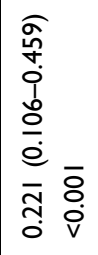 & 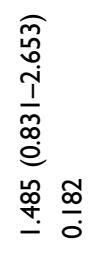 \\
\hline 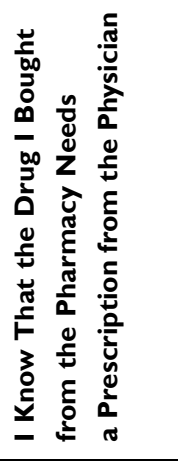 & 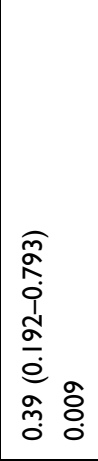 & 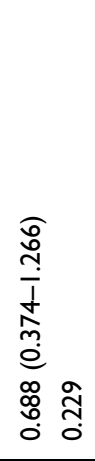 \\
\hline 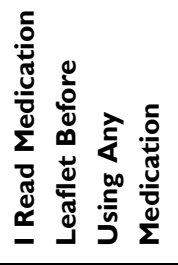 & 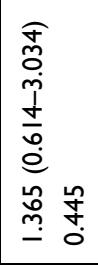 & 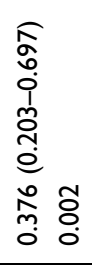 \\
\hline 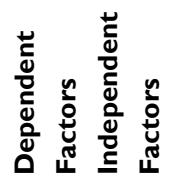 & 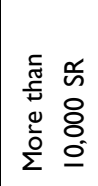 & 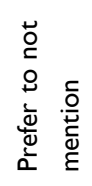 \\
\hline
\end{tabular}

students in the age 19-21 year age group were significantly more likely to say that using acetaminophen products $\left(\right.$ Panadol $\left.^{\circledR}\right)$ was safe during examinations $(\mathrm{p}<0.001$, OR: 0.16, CI: $0.065-0.39$ ) and that many students may try medicines due to their friends' suggestions $(\mathrm{p}<0.05$, OR: 0.27 , CI: $0.11-0.67)$. The participants with family incomes higher than 10,000 SR reported reading the medication leaflet 1.3 times more than other groups $(\mathrm{p}<0.44$, OR: 1.36, CI: $0.61-3.03)$, and they were significantly less affected by advertisements for OTC drugs $(\mathrm{p}<0.05$, OR: 0.32 , CI: $0.15-0.66$ ).

\section{Discussion}

During the examination period, university students experience higher levels of tension and stress compared with normal school days. These factors can contribute to adverse reactions, such as headaches, which can result in the loss of study days, impaired academic performance, and poor quality of life. ${ }^{16-18}$ The prevalence of selfreported headaches among university students in Saudi Arabia, as reported in two previous studies, was $68.4 \%$ and $77 \%{ }^{19,20}$ Most respondents in our current study revealed that they would practice self-medication to treat headaches during the examination period $(85.3 \%$ and $86.2 \%$, respectively). This finding is similar to a previous study conducted in Oslo, Norway, in which OTC NSAIDs and Panadol were favored for use in treating headache and general pain during examinations. ${ }^{21}$

The prevalence of self-medication using analgesics among university students could differ from one study to another due to various factors, including differences in study design, the ages of participants, differences in the classifications of drugs as OTC versus prescription between countries, and others. In general, the Saudi population can easily buy OTC analgesics because community pharmacies are accessible and widely distributed. ${ }^{7,12}$ As a result, our study findings showed a high incidence of OTC drug use and self-medication practice during the exam period $(85.3 \%)$. This result was comparable to a previous study, which reported that $80 \%$ of students use OTC NSAIDs during examinations. ${ }^{11}$ Another study found that $86.6 \%$ of male students at Qassim University, Saudi Arabia practiced self-medication. However, our results showed a higher OTC self-medication rate among students than those reported by other studies conducted in various developing countries, such as $43.2 \%$ in Ethiopia, $51 \%$ in Slovenia, $55 \%$ in Egypt, $56.9 \%$ in Nigeria, and $78.1 \%$ in Bangladesh. ${ }^{22-27}$ 
In addition, our respondents are aware of proper OTC use because they are convenient and easy to use (68\%), and most of the respondents felt comfortable consulting with the pharmacist $(82.7 \%)$. These factors may explain the higher incidence of self-medication practice observed among students during the examination period. Previous studies revealed that female students were more likely to use OTC drugs as a form of self-medication practice than male students. ${ }^{11,28}$

One of the main aims of this study was to identify the factors that may contribute to the increased incidence of self-medication practice using OTC drugs among students during the exam period. The results of this study indicated three types of effectors: time, community pharmacy, and media/advertisement. In the time-related context, the findings reveal that the use of certain medicines was viewed as saving time, especially during the examination period (80.1\%). A majority $(90.3 \%)$ of participants agreed that students might use antihistamine drugs to provide a sedative effect during exams. This finding indicates that sleep pattern disturbances are a compelling factor driving the non-prescription use of OTC drugs, especially during examinations. These findings were similar to those of a previous study, in which $80 \%$ of students reported using antihistamines for their sedative effects. Our study showed that the availability of OTC drugs and the view of these drugs as being safe were the primary reasons why students choose to use OTC drugs during examinations (75.8\%), which may be associated with the availability and ease of access of OTC drugs at community pharmacies in Saudi Arabia. No networking system exists among community pharmacies to limit the overuse of medications by customers in Saudi Arabia. The final effector was the media, which appeared to drive consumer choice toward OTC drug use. In our study, $66.3 \%$ of students indicated that they would buy OTC drugs due to advertisements on social media and TV. A previous study found that advertisements directly affect a youths' decision to practice selfmedication. ${ }^{29}$ Furthermore, academic stress may be a motivator for students who utilize self-medication practices. ${ }^{30}$ Although the present study's objective was not intended to measure academic stress, students' academic responsibilities can prevent them from getting professional advice, as students believe that consulting a physician is expensive and time-consuming.

\section{Limitations of the Study}

Because this study was performed as a cross-sectional study, no definitive cause and effect associations can be determined between OTC drug use and various factors. Although the sampling was conducted randomly and during the final examination period, the study may be subjected to recall bias because the respondents must recall their OTC drug use patterns, in addition to reporting their drug use patterns during the examination period. The study was conducted among students attending one university in the Southern region of Saudi Arabia. More studies are necessary to reflect a clearer image of OTC drug use during examinations.

\section{Conclusion}

A high prevalence of OTC self-medication practice was reported during the exam period, and the majority of students opted against seeking medical care due to timeand cost-associated reasons. Most of the respondents consumed analgesics to treat headaches and help them sleep, driven by advertisements and advice from friends. The easy accessibility of community pharmacies and OTC drugs are the main reasons underlying the high incidence rate of self-medication practices among university students. Among the student population, headache is becoming the most debilitating and difficult health problem. Although the majority of students were aware of the dangers of using OTC drugs, policymakers, academic officials, health professionals, and all other concerned bodies should devote adequate attention to developing preventive and therapeutic strategies to manage the use of OTC drugs during examinations.

\section{Funding}

The authors are thankful to deanship of research at King Khalid University for supporting this research through grant number \# R.G.P.I/209/41.

\section{Disclosure}

The authors reported no conflicts of interest for this work.

\section{References}

1. World Health Organization. The role of the pharmacist in self - care and self-medication. Report of the 4th WHO Consultative Group on the Role of the Pharmacist. The Hague, 1998. Available from: http://www.who.int/ medicines/library/dap/who-dap-98-13/who-dap-98-13.pdf.

2. Pawaskar MD, Balkrishnan R. Switching from prescription to over the counter medications: a consumer and managed care perspective. Manag Care Interface. 2007;20:40-47.

3. WHO Guideline for the Regulatory Assessment of Medicinal Products for Use in Self- Medication, 2000. Available from: www.who.int/ medicines/library/qsm/who-edm-qsm-2000-1/who-edm-qsm-00_1.ht. 
4. Aljadhey H, Assiri GA, Mahmoud MA, Al-Aqeel S, Murray M. Selfmedication in Central Saudi Arabia. Community Pharmacy Consumers' Perspectives. Saudi Med J. 2015;36(3):328-334.

5. Zafar SN, Reema S, Sana W, et al. Self-medication amongst university students of Karachi: prevalence, knowledge and attitudes. JPMA. 2008;58(4):214-217.

6. Bennadi D. Self-medication: a current challenge. J Basic Clin Pharm. 2013;5(1):19-23.

7. Alshahrani SM, Alakhali KM, Al-Worafi YM, et al. Awareness and use of over the counter analgesic medication: a survey in the Aseer region population, Saudi Arabia. Int J Advan Appl Sci. 2020;7(3):130-134.

8. Kagashe GA, Francis L. Dispensing of drugs with and without a prescription from private pharmacies in Dar es Salaam. Tanzania Med J. 2004;19(1):36-39.

9. Alghanim SA. Self-medication practice among patients in a public health care system. East Mediterr Health J. 2011;17(5):409-416.

10. Al-Ghamdi S, Alfauri TM, Alharbi MA, et al. Current self-medication practices in the Kingdom of Saudi Arabia: an observational study. Pan Afr Med J. 2020;37:51.

11. Almalak H, Albluwi AI, Alkhelb DA, et al. Students' attitude toward use of over the counter medicines during examinations in Saudi Arabia. Saudi Pharm J. 2014;22(2):107-112.

12. Alshahrani SM, Alavudeen SS, Alakhali KM, Al-Worafi YM, Bahamdan AK, Self-Medication Among VE. King Khalid University Students, Saudi Arabia. Risk Manag Healthc Policy. 2019;12:243-249.

13. Zafar SN, Syed R, Waqar S, et al. Self-medication amongst university students of Karachi: prevalence, knowledge and attitudes. J Pak Med Assoc. 2008;58(4):214-217.

14. Joffe A. Your role in curbing prescription and OTC drug abuse by adolescents. Contemp Pediatr. 2006;23:97-101.

15. Albusalih FA, Naqvi AA, Ahmad R, Ahmad N. Prevalence of self-medication among students of pharmacy and medicine Colleges of a Public Sector University in Dammam City, Saudi Arabia. Pharmacy (Basel). 2017;5(3):51.

16. Nandha R, Chhabra MK. Prevalence and clinical characteristics of headache in dental students of a tertiary care teaching dental hospital in Northern India. Int J Basic Clin Pharmacol. 2013;2(1):51-55.

17. Birru EM, Abay Z, Abdelwuhab M, Basazn A, Betelhem Sirak B, Teni FS. Management of headache and associated factors among undergraduate medicine and health science students of University of Gondar, North West Ethiopia. J Headache Pain. 2016;17:56-65.
18. Souza-e-Silva HR, Rocha-Filho PA. Headaches and academic performance in university students: a cross-sectional study. Headache. 2011;51:1493-1502.

19. Desouky DE, Zaid HA, Taha AA. Migraine, tension-type headache, and depression among Saudi female students in Taif University. J Egypt Public Health Assoc. 2019;94:7.

20. Al-Hassanl ES, Al-Mulifi AA, Al-Khudhayr AM, et al. Prevalence of headache in female students in King Faisal University: a questionnaire study. Int J Sci Res. 2013;5(6):256-260.

21. Rosvold Elin. O. Self-reported use of medicines among university students in Oslo. Norway Norsk Epidemiolog. 2008;18(2):195-199.

22. Saeed MS, Alkhoshaiban AS, Al-Worafi YM, Long CM. Perception of self-medication among university students in Saudi Arabia. Arch Pharm Pract. 2014;5(4):149.2.

23. Gutema GB, Gadisa DA, Kidanemariam ZA, et al. Self-medication practices among health sciences students: the case of Mekelle University. J Appl Pharmaceutical Sci. 2011;01(10):183-189.

24. Smogavec M, Softič N, Kersnik J, Klemenc-Ketiš Z. An overview of self-treatment and selfmedication practices among Slovenian citizens. Slovenian Med J. 2010;79:757-763.

25. El Ezz NF, Ez-Elarab HS. Knowledge, attitude and practice of medical students towards self-medication at Ain Shams University. Egypt J Prev Med Hyg. 2011;52(4):196-200.

26. Fadare JO, Tamuno I. Antibiotic self-medication among university medical undergraduates in Northern Nigeria. $J$ Public Health Epidemiol. 2011;3(5):217-220.

27. Nasir M, Zahan T, Parvin RA. Comparative study on knowledge, attitude and practice of selfmedication among the medical and non-medical undergraduate students in Dhaka city. WJPLS. 2017;4 (3):17-20.

28. Abahussain E, Matowe Lloyd K, Nicholls PJ. Self-reported medication use among adolescents in Kuwait. Med Princ Pract. 2005;14:161-164.

29. Burak LJ, Damico A. College students' use of widely advertised medications. J Am Coll Health. 2000;49:118-121.

30. Eissa A. Knowledge, attitudes and practices towards medication use among health care students in King Saud University. Int J Med Stud. 2013;1:66-69.
Risk Management and Healthcare Policy

\section{Publish your work in this journal}

Risk Management and Healthcare Policy is an international, peerreviewed, open access journal focusing on all aspects of public health, policy, and preventative measures to promote good health and improve morbidity and mortality in the population. The journal welcomes submitted papers covering original research, basic science, clinical \& epidemiological studies, reviews and evaluations,

\section{Dovepress}

guidelines, expert opinion and commentary, case reports and extended reports. The manuscript management system is completely online and includes a very quick and fair peer-review system, which is all easy to use. Visit http://www.dovepress.com/testimonials.php to read real quotes from published authors. 